\title{
Modeling the effects of vector control interventions in reducing malaria transmission, morbidity and mortality
}

\author{
Nakul Chitnis ${ }^{1,2}$, Diggory Hardy ${ }^{1,2}$, Guillaume Gnaegi ${ }^{1,2}$, Konstantina Boutsika $^{1,2^{*}}$, Nicolas Maire ${ }^{1,2}$, Richard Steketee ${ }^{3}$, \\ Allan Schapira ${ }^{1,2}$, Tom Smith ${ }^{1,2}$ \\ From Parasite to Prevention: Advances in the understanding of malaria \\ Edinburgh, UK. 20-22 October 2010
}

Malaria interventions are usually prioritized using efficacy estimates from intervention trials, without considering the context of existing intervention packages or long-term dynamics. We use numerical simulation of mathematical models of malaria in humans and mosquitoes to provide robust quantitative predictions of effectiveness of different strategies in reducing transmission, morbidity and mortality.

We can simulate indoor residual spraying (IRS) and insecticide-treated nets (ITNs), used singly and in combination with each other and with other interventions such as improved case management, intermittent preventive treatment (IPT). We can estimate reductions in entomological inoculation rate (EIR), clinical cases, prevalence and malaria deaths from simulations of different coverage levels ITNs and IRS with different properties, and at different transmission and health system settings.

Our results suggest that sustained coverage of one or two interventions reduces malaria prevalence in two to three years but does not lead to further gains (Figure 1). However, in some settings, even with sustained coverage, clinical incidence of malaria increases as the population loses its naturally acquired immunity. In some low to medium transmission settings, our simulations suggest that high coverage of both interventions can lead to interruption of transmission.

\section{Author details}

1 Department of Epidemiology and Public Health, Swiss Tropical and Public Health Institute, P.O. Box, CH-4002 Basel, Switzerland. 'University of Basel,

'Department of Epidemiology and Public Health, Swiss Tropical and Public Health Institute, P.O. Box, CH-4002 Basel, Switzerland

Full list of author information is available at the end of the article
P.O. Box, CH-4003 Basel, Switzerland. ${ }^{3}$ MACEPA-PATH, 01210 Ferney Voltaire, France.

Published: 20 October 2010

\section{References}

1. Smith T, Killeen DF, Maire N, Ross A, Molineaux L, Tediosi F, Hutton G, Utzinger J, Dietz K, Tanner M: Mathematical modeling of the impact of malaria vaccines on the clinical epidemiology and natural history of Plasmodium falciparum malaria: overview. Am J Trop Med Hyg 2006, 75(2 Suppl):1-10.

2. Chitnis N, Smith T, Steketee RW: A mathematical model for the dynamics of malaria in mosquitoes feeding on a heterogeneous host population. $J$ Biol Dyn 2008, 2:259-285.

3. Chitnis N, Schapira A, Smith T, Steketee R: Comparing the effectiveness of malaria vector control interventions through a mathematical model. Am J Trop Med Hyg 2010, 83:230-40.

doi:10.1186/1475-2875-9-S2-07

Cite this article as: Chitnis et al: Modeling the effects of vector control interventions in reducing malaria transmission, morbidity and mortality. Malaria Journal 2010 9(Suppl 2):O7.

\section{Submit your next manuscript to BioMed Central and take full advantage of: \\ - Convenient online submission \\ - Thorough peer review \\ - No space constraints or color figure charges \\ - Immediate publication on acceptance \\ - Inclusion in PubMed, CAS, Scopus and Google Scholar \\ - Research which is freely available for redistribution \\ Submit your manuscript at www.biomedcentral.com/submit \\ C Biomed Central}

( 2010 Boutsika et al; licensee BioMed Central Ltd. This is an open access article distributed under the terms of the Creative Commons 


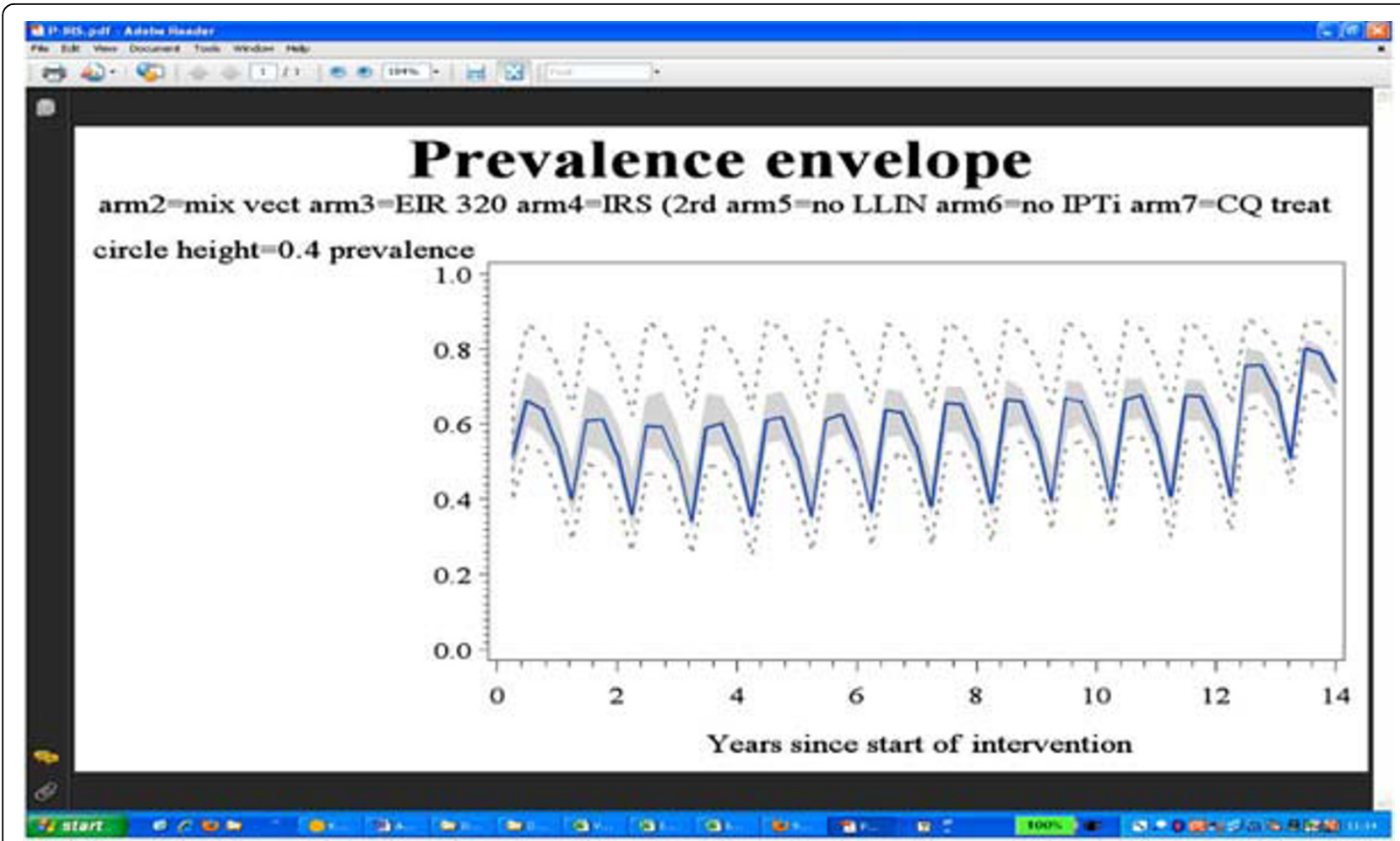

Figure 1 Model predictions of the effect of IRS with DDT on malaria prevalence. We assume two annual IRS DDT spray rounds (each with $95 \%$ coverage) for 12 years; simulations are of 1000 humans exposed to seasonal transmission based on a Tanzanian setting, with an initial EIR of 320 infectious bites per person per annum. The blue line is the median prevalence from four runs of each of 15 different model paramerizations for malaria in humans; grey area: interquartile range; dashed lines: maxima and minima. 